Acta Poetica 27 (2)

OTOÑO

2006

\title{
In memoriam: entre cerdos y búhos (o los viejos: nuestro futuro)
}

\author{
Silvana Rabinovich
}

El presente artículo, siguiendo el planteamiento de Jean-Yves y Marc Tadié en su libro Le sens de la mémoire, explora a la memoria en tanto sentido: sentido físico junto a los cinco conocidos, sentido como significado del sujeto y sentido como dirección de la memoria en el tiempo.

Estas reflexiones cuestionan la conocida "pérdida de memoria" atribuida a la vejez, a fin de sostener que si bien el aspecto instrumental de la memoria se ve afectado con el paso de los años, este fenómeno da lugar al desarrollo de otras formas de la memoria.

Jean-Yves Tadié es el reconocido curador de la obra de Proust. Su hermano Marc es neurocirujano. Juntos han hecho una amplia y profunda incursión interdisciplinaria en el tema de la memoria. Este artículo se acerca a textos literarios diversos (una novela y un cuento de Adolfo Bioy Casares, algunos poemas de Baudelaire, la narrativa de Felisberto Hernández), así como también a problemas éticos y políticos que conciernen a la vejez y a la memoria, con el fin de entretejerlos en reflexiones que giran en torno a la memoria como sentido.

Following Jean-Yves' and Marc Tadié's ideas in their book Le sens de la mémoire, this article explores memory as a sense: a physical sense along with the other five senses; sense as the meaning of subjectivity and sense as a direction of memory in the time dimension.

These reflections aim at questioning the well-known "memory loss" associated with old age. We argue that, even though the instrumental aspect of memory is affected by aging, this phenomenon enables the development of other forms of memory.

Jean-Yves Tadié is well-known as the curator of Proust works, and his brother Marc, as a neurosurgeon. Together, they achieved a wide and deep interdisciplinary approach on memory. This article addresses various literary texts (a novel and a short story by Adolfo Bioy Casares, some poems by Baudelaire, and Felisberto Hernández' narrative texts) as well as ethical and political issues related to memory and old age, and intertwines them with thoughts on memory as a sense. 



\section{Silvana Rabinovich \\ Instituto de Investigaciones Filológicas, UNAM \\ In memoriam: entre cerdos y búhos (o los viejos: nuestro futuro)}

Para Ana y Wolf Kaufman, cuyos "pensamientos descalzos" me acompañarán siempre.

Para Carlos Rabinovich y Cecilia Kaufman,

a quienes no pude ver envejecer.

¡Ruinas! ¡Familia mía! ¡Oh cerebros congéneres! ¡Os hago cada día un solemne adiós! ¿Dónde estaréis mañana, Evas octogenarias, sobre quienes pesa la garra aterradora de Dios?

BAUDELAIRE $^{1}$

\section{Aclaraciones preliminares}

En el siguiente trabajo se aborda a la vejez en tanto fragilidad y pobreza (que se desprenden del sentido económico de la tercera

1 "Las viejecitas", IV, en Cuadros parisienses [Tableaux parisiens], edición bilingüe, trad. E. Parellada [Ruines! ma famille! ô cerveaux congénères! / Je vous fais chaque soir un solennel adieu! / Où serez-vous-demain, Èves octogénaires, / Sur qui pèse la griffe effroyable de Dieu?]. 
edad como sector pasivo de la población). No hay intención de aproximarse a la cara autoritaria de la vejez, proveniente de la gerontocracia ya que, recordando a Cicerón, entendemos que las imprudencias de la vejez remiten a un pasado adulto imprudente y no a una característica esencial de la edad. Cabe aclarar también que este planteamiento del lugar de los viejos en nuestras sociedades industrializadas (o maquileras) gira en torno a la imagen del ser humano en tanto productivo, y responde a una concepción instrumental tanto del tiempo como de la memoria. Desde una perspectiva histórico-social de la vejez $^{2}$ en conjunción con la ética heterónoma levinasiana, el presente trabajo trata de aproximarse de otro modo tanto a la concepción de la vejez, como a las nociones de la memoria y el tiempo.

Coinciden los hermanos Tadié, desde la literatura uno y desde la medicina el otro, en que la memoria es un sentido, junto a los cinco conocidos, y éste concierne al porvenir. El sentido de la memoria ${ }^{3}$ (que da el título al libro), como tal, explora todas las potencialidades semánticas del término: sentido corporal, sentido como dirección y también como significación. Poniendo al desnudo el tiempo como problema, dedicaremos las reflexiones que siguen a nuestro futuro (que en términos generacionales no son, como creen entender los políticos, los jóvenes ni los niños): lo dedicamos a los — “olvidadizos"- hombres y mujeres "en pasado".

En el Diario de la guerra del cerdo ${ }^{4}$ de Adolfo Bioy Casares, los jóvenes van a la caza de los viejos con la intención de

\footnotetext{
${ }^{2}$ Véase Alba 1992; Minois 1987; Salvarezza 2000; Sánchez-Salgado 2000; Benoit-Lapierre et al. 1980; Thomas 1992. Me permito remitir al artículo "Vieillesse" que escribí en el Dictionnaire Critique de la Mondialisation, Paris, Le Pré aux Clercs, GERM, 2001.

${ }^{3}$ Tadié 1999.

${ }^{4}$ Bioy Casares 1997.
} 
terminar con ellos. Se trata de una especie de "limpieza" de la población "pasiva". Algunos la llaman "la guerra del búho", en alusión a la sabiduría de los viejos; la mayoría conoce a este exterminio como "la guerra del cerdo" (en referencia a los supuestamente injustificados y anacrónicos deseos sexuales de este sector de la población). Seres desmemoriados, detríticos, los viejos aparecen como una carga social que la ficción logra desenmascarar con crudeza. El tema de las políticas gubernamentales respecto del problema de la vejez vuelve en el cuento "Planes para una fuga al Carmelo", 5 una de las Historias desaforadas del mismo autor, donde el Uruguay, sobre la otra rivera del Río de la Plata, se vuelve asilo para ancianos. Allá en el oriente, del otro margen del "río sin orillas", descubrieron el secreto de la inmortalidad, pero no el que detiene el envejecimiento. La paradójica "salvación" —en manos de un tal Moureira - lleva al profesor Félix Hernández rumbo al envejecimiento infinito. En ambas historias el viejo es agraciado por el amor de una mujer joven, pero su soledad es inexorable. Si visitara la novela, el profesor Félix Hernández (protagonista del cuento) sería un búho "subversivo", que dice verdades odiosas para sus contemporáneos, por ejemplo: "Las universidades, que fueron ciudadelas del saber, se convirtieron en oficinas de expendio de patentes. Nada vale menos que un título universitario". ${ }^{6}$ Así, la ficción transmite con veracidad un proceso del que todos somos testigos: los viejos se vuelven inasimilables dentro de un cuerpo social de cara a la industrialización, que no sabe qué hacer con ellos, su presencia duele porque insiste en recordar lo que el presente tiene urgencia de olvidar. En sus arrugados rostros los ancianos cuestionan el sentido instrumental de la memoria, a la vez que exhiben de manera obscena la fragilidad del sujeto: "El fin del postrer

${ }^{5}$ Bioy Casares 1997.

6 Bioy Casares 1997, 297 ("patente” en Argentina, además de registro significa "placa", por ejemplo de un vehículo). 
acto, con que remata la azarosa historia es la segunda infancia, un puro olvido, dientes, ojos, gusto y todo falta". 7 Y porque la vejez no es desmemoria, sino memoria indeseada por quienes no quieren escucharla; ni tampoco es sinsentido, porque tiene otro sentido diferente al que privilegia nuestra sociedad adultocéntrica, nos aproximaremos a la memoria como sentido.

\section{1. (Primer "sentido" de la palabra) \\ La memoria: nuestro sexto sentido}

La memoria es un sentido: aquel en el que se funden todos los otros para hacernos felices o desdichados, alegres o tristes, atrevidos o apáticos. Se puede sentir (o percibir) sin memoria pero no se puede experimentar (ressentir) sin ella. Nuestros recuerdos nos permiten interpretar nuestras sensaciones, relacionarlas entre ellas, fundirlas en un solo sentido que es el de la memoria y que produce la impresión de que vivenciamos (ressentons). ${ }^{8}$

La memoria entendida como sentido es la posibilidad de reconocer percepciones, de volver a experimentar sentimientos pasados. Antiguas sensaciones que dan cuenta de momentos en los que el cuerpo propio se expuso ante percepciones provenientes del exterior. Sólo a partir de la memoria de sensaciones pasadas cobran significado sensaciones presentes, y éstas se proyectan en un futuro. Se trata de la memoria sensitiva, compañera inseparable de la memoria involuntaria (Proust ofrece muchos ejemplos). Si en la vejez, como escribe Shakespeare,

\footnotetext{
${ }^{7}$ Shakespeare 1999, 146, segundo acto.

${ }^{8}$ [La mémoire est un sens: celui dans lequel se fondent tous les autres pour nous rendre heureux ou malheureux, gais ou tristes, entreprenants ou apathiques. On peut sentir sans mémoire mais on ne peut pas ressentir sans elle. Ce sont nos souvenirs qui nous permettent d'interpréter nos sensations, de les lier entre elles, de les fondre en un seul sens qui est celui de la mémoire et qui produit l'impression que nous ressentons] (Tadié 1999, 314; la traducción es mía).
} 
algunos de los cinco sentidos se ven vulnerados con el paso implacable del tiempo, este sexto sentido que atesora y teje experiencias pasadas, frecuentemente - cuando las experiencias presentes se resisten- se vuelve introvertido, ensimismado, podríamos decir: jorobado. Vuelto hacia las sensaciones pasadas, como el miope doblegado ante la lectura, o el sordo con el oído (y el cuerpo) tendido hacia la voz, el recuerdo sin porvenir espera paciente lo que le ha de sobrevenir. Pero que este sentido de la memoria se encuentre ensimismado no nos permite apresurarnos a anunciar su desaparición o su inercia sino que nos obliga a atender su sigilo.

Felisberto Hernández 9 alude a los "pensamientos descalzos" que habitan en el cuerpo:

Yo creo que en todo el cuerpo habitan pensamientos, aunque no todos vayan a la cabeza y se vistan de palabras. Yo sé que por el cuerpo andan pensamientos descalzos. Cuando los ojos parecen estar ausentes porque su mirada está perdida y porque la inteligencia se ha retirado de ellos por unos instantes y los ha dejado vacíos, y mientras los pensamientos de la cabeza deliberan a puerta cerrada, los pensamientos descalzos suben por el cuerpo y se instalan en los ojos. Desde allí buscan un objeto para clavarle la mirada y parecen víboras que hipnotizan pájaros. También hipnotizan a los pensamientos que están encerrados y éstos tienen que abandonar sus deliberaciones.

Tal vez, a partir de este texto, podamos pensar que cuando — desde nuestra mirada adultocéntrica - consideramos que la memoria del jubilado "se encuentra jorobada"; en lugar de estar decrépita, ésta se encuentre más activa que nunca, pero de otro modo, protagonizando una orgía de "pensamientos descalzos". A fuerza de planificar (esto es, de abordar el mundo de manera plana), nuestra sociedad cree deberle su estatura a los

${ }^{9}$ Véase Hernández 1999. 
pensamientos elegantemente vestidos y calzados, privilegiando así una memoria instrumental, pero esta última emigró hacia el territorio electrónico hace tiempo. Ya lo advertía Cicerón: ${ }^{10}$ si el viejo cuerpo ya no puede hacer ejercicios, la memoria puede y debe ejercitarse. Pero la pregunta — pensada de manera tridimensional, esto es, tomando en cuenta la profundidad abismal del tiempo- es qué parte de su compleja composición se ejercita y cómo. Retirarse de lo que en términos bípedos y bidimensionales se da en llamar "vida activa", abre sin duda la puerta a algo que en el "sector pasivo" de esos que según el enigma de la Esfinge andan en tres patas, puede pensarse (en palabras levinasianas) como "ejercicios de paciencia".

En el hecho de que los viejos se ensimismen en recuerdos lejanos, sin expectativas reconocibles por quienes los rodean, resuena políticamente la descripción que hace Koselleck (p. 278) de los "sueños utópicos de campos de concentración" en los cuales "la pura facticidad del campo se extingue, el pasado quiere trasladarse al futuro. Esos sueños eran presagios de muerte". Esto no significa que la vida de los ancianos en las sociedades industrializadas pueda o deba asimilarse a la de los prisioneros de los campos de concentración; sin embargo, la sospecha de subhumanidad o, más poéticamente, del viejo como "hombre en pasado" tiene resonancias que Bioy Casares dramatizó en su Diario de la guerra del cerdo.

La novela de Elie Wiesel El olvidado ${ }^{11}$ está narrada por un hijo que se encuentra obligado a volverse hacia el pasado ante la grave "pérdida de la memoria" que acosa a su padre (probablemente el mal de Alzheimer). En lugar de conformarse con las limitaciones vistas desde el lamentable proceso que sufre su padre, el hijo sospecha que lo que se pierde está precisamente de su lado:

\footnotetext{
10 Cicerón 1997.

11 Wiesel 1994.
} 
Puede que le haya decepcionado la humanidad y su lenguaje. Puede que rechace nuestras palabras, $\tan$ gastadas, tan devaluadas. Puede que le hagan falta otras. Y como no tiene ninguna, puede que haya tomado el partido de fingir el olvido para callarse. ${ }^{12}$

Este enmudecimiento del anciano (y la lectura que de él hace el hijo) tiene un correlato político en el ejemplo extremo que da Koselleck ${ }^{13}$ en su capítulo sobre "sueño y terror", que atañe a una situación (política, pero que es consecuencia de un abordaje infrahumano del otro) en la que "el lenguaje enmudece y las dimensiones del tiempo parecen confundirse". Aunque parezca extraña esta relación, la memoria "individual" se encuentra atravesada por lo político. La decepción del viejo en la novela de Wiesel se relaciona con la guerra, pero hay otras formas en que se entretejen memorias y guerras. ${ }^{14}$ Susan Sontag abordó de manera cabal esta relación compleja entre la enfermedad y lo político. ${ }^{15}$

La memoria como sentido, condición de posibilidad de los sentidos del cuerpo, se ve afectada en estos casos por cuestiones que no son ajenas al lugar de la vejez en la polis. Por ello el anciano se encamina en una dirección diferente: de cara al pasado, se refugia de los embates de un porvenir excluyente, a fin de rescatar algo que le permita, todavía, hablar desde la vibración de un "yo".

12 Ibidem, 319.

${ }^{13}$ Koselleck 1993, 272-281, capítulo "Sueños de terror, sueños en el terror"; la cita en la p. 17.

${ }^{14}$ En otro trabajo llamé heteronomía de la memoria a la memoria intersubjetiva, aquella que sin decidirlo se hace cargo de memorias de otros: memoria política que carga sin saberlo con las experiencias de guerras pasadas por generaciones anteriores. Véase "La transmisión de lo indecible", en De memoria y escritura (Esther Cohen y Ana María Martínez de la Escalera, coords.), México, IIFL-UNAM, 2002, pp. 47-63.

${ }^{15} \mathrm{Si}$ bien no se refiere al mal de Alzheimer, es importante pensarlo desde esta perspectiva. Véase Sontag 1996. 


\section{2. (Segundo "sentido")}

La memoria como significación del sujeto

Pero ¿qué es el hombre privado de su memoria? Ni siquiera un fantasma...

ELIE WIESEL

Éste sería el significado fenomenológico del "sentido de la memoria". Lo propiamente humano es la sujeción a un pasado (y a sus contemporáneos, y a los que vendrán). La memoria, más allá de la dicotomía individual-colectiva, se da de manera intersubjetiva y espectral. Amar es un estado de la memoria, todo lo que damos intenta dejar marcada una huella en el recuerdo del otro, y en el porvenir. Y si la memoria es el lugar donde el sujeto cobra sentido, esta significación es válida sólo en relación con los otros... para poder contarla, para transmitir. Pero la sujeción al pasado no debe entenderse como lo contrario de la libertad: esta última es posible también gracias a la memoria (especialmente a la memoria voluntaria). Toda elección tiene lugar como selección operada en función de lo que se recuerda y se reconoce (aun cuando estos contenidos son del orden de un anhelo acariciado), y sólo cuando el recuerdo - voluntario e involuntario - acude, puede abrirse el presente al porvenir, tener la sensibilidad de acoger lo nuevo. Claro que en la selección, el olvido es aquel que asegura la preeminencia de aquello que la memoria desea recuperar. No se trata simplemente de términos opuestos; existe una extraña solidaridad entre memoria y olvido. ${ }^{16}$

${ }^{16}$ El olvido, como Nietzsche indica en la consideración intempestiva sobre las utilidades y perjuicios de la historia para la vida, es necesario, vital. No es tema de este trabajo la perspectiva del olvido sino la de la memoria (y su supuesta pérdida en la vejez), sin embargo es importante aclarar que la perspectiva desde la que se escribe este artículo rechaza todo abordaje binario que vea de manera positiva a la memoria y al olvido como negativo (si bien en el caso de la novela $E l$ olvidado se privilegia esta oposición por causas patológicas). Memoria y olvido son inseparables: el olvido hace posible la memoria, y el pensamiento (eso queda 
La pérdida paulatina de la memoria — es decir, la pérdida de la subjetividad - es transmitida por Wiesel de manera cabal a través de una imagen: "una mano demoníaca arrancaba una tras otras las páginas de su libro". ${ }^{17} \mathrm{El}$ sujeto, contrario a la imagen de trillado optimismo, que describe un libro en blanco abierto a la escritura del porvenir, es un libro escrito desde tiempos inmemoriales y por autores ancestrales, y ese libro - siempre por descifrar - se deshoja. Esta aproximación a la memoria, a la escritura y al olvido es familiar y a la vez extraña a la concepción platónica de la memoria: si bien según el griego en La República lo que constituye al sujeto es el esfuerzo por recordar aquello que el alma conoció en el mundo de las ideas, ${ }^{18}$ la escritura en el Fedro se devela como una mnemotecnia traicionera que asegura el olvido. Que el autor de El olvidado defina al sujeto (segundo sentido de la memoria) bajo la imagen del libro que se deshoja, descarna a la memoria platónica de todo optimismo.

Qué importa. Sólo cuenta la memoria. La mía se desborda a veces. Es porque pesa más que mis propios recuerdos. Envuelve y protege también la de mi padre. La memoria de mi padre es un colador. No, un colador no. Una hoja de otoño. Marchita. Agujereada. No, es más bien un fantasma. Sólo la veo a medianoche. Lo sé: no se puede ver una memoria. Pero yo puedo. La veo como la sombra de una sombra que incesantemente se retira, se repliega sobre sí misma. Apenas la he percibido cuando se pierde en un abismo. Luego la oigo gritar, la oigo gemir suavemente. Ya no está ahí, pero la veo como me veo a mí mismo. Me llama: Malkiel, Malkiel. Y yo respondo: no tengas miedo, no te abandonaré.

Un día ya no me llamará. ${ }^{19}$

demostrado en el personaje borgeano de Funes el memorioso, aquel que por recordarlo todo simultáneamente era incapaz de pensar, ya que, de manera nietzscheana, Borges afirma "pensar es olvidar diferencias").

17 Wiesel 1994, 317.

${ }^{18}$ Véase Platón, República, Libro X.

${ }^{19}$ Wiesel 1994, 13. 
La relación con el otro está entretejida de memoria, en palabras de Tadié: "Nuestra verdadera tumba es la memoria de los vivos, estamos muertos verdaderamente cuando nos han olvidado". ${ }^{20}$ Wiesel, desde otra perspectiva, se pregunta: “ $¿$ Y si la vida sólo fuese la imaginación de los antepasados o el sueño de los muertos?"21

La memoria es inherente al tiempo, según Tadié: "la memoria, al explorar el pasado, prepara el porvenir identificando al presente". ${ }^{22}$ Nuestras experiencias presentes tienen el tono de aquello en que nuestra memoria pone el acento, la memoria pone al descubierto, no la linealidad ni la circularidad, sino una cierta maraña del tiempo. En otra parte escriben los autores: "nuestro pasado condiciona las características de nuestros futuros recuerdos". Agregaríamos que el sujeto, desde esta perspectiva, experimenta la idea mesiánica del "tiempo lleno": en el que todo instante actual es visitado por el pasado y por el porvenir; sólo es cuestión de percibirlo. Pero en la planicie de nuestra cultura la idea de un voluminoso tiempo lleno se considera un tumor extirpable o, en el mejor de los casos, una joroba...23

\footnotetext{
${ }^{20}$ [Notre vraie tombe est la mémoire des vivants, nous sommes véritablement morts quand ils nous ont oubliés] (Tadié 1999, 332).

${ }^{21}$ Wiesel 1994, 15.

22 [La mémoire, explorant le passé, prépare l'avenir tout en identifiant le présent] (325).

${ }^{23}$ Véase Benjamin 1971. Benjamin escribe sus tesis como consecuencia de la emblemática traición perpetrada por el pacto de no agresión germano-soviético, firmado en Moscú por Von Ribentropp y Molotov en el año 1938; este acuerdo en principio duraría 10 años. Hasta ese momento, Europa dependía de la Unión Soviética para detener al fascismo. Este pacto aniquilaba toda esperanza. Benjamin se suicidó en 1940, el mencionado pacto fue roto por Hitler en 1941. La primera de las tesis benjaminianas alude a un "enano jorobado", impresentable pero el único posible redentor del momento político en que escribe: la teología sería ese jorobadito que sin ser visto, oculto debajo de la mesa de juego, movería los hilos de la marioneta llamada "materialismo histórico". Intempestivo, Benjamin fue capaz de pensar en 1940 la relación entre lo mesiánico-cabalístico y el pensamiento de Marx.
} 
El poeta Baudelaire expresa con crudeza el desolado "sexto sentido" del anciano, que tiene que ver con un recuerdo rancio, esa memoria indeseada de los ancianos a la que aludimos antes. Una memoria vieja confiesa el veneno que roe al sujeto, vuelto un viejo frasco de cristal cuyas paredes se volvieron porosas y que retribuye al mundo con la "amable pestilencia" que lo acogió. El material corrosivo no es ajeno a la memoria, sino que le es esencial (el libro-sujeto de El olvidado cada día perdía una página, no se especificaba si la corrosión le era sustancial o accidental; en "El frasco" de Baudelaire no hay duda de que la memoria tiene un aspecto esencialmente corrosivo):

\section{LE FLACON \\ Charles Baudelaire ${ }^{24}$}

Il est de forts parfums pour qui toute matière Est poreuse. On dirait qu'ils pénètrent le verre.

En ouvrant un coffret venu de l'Orient

Dont la serrure grince et rechigne en criant,

Ou dans une maison déserte quelque armoire

Pleine de l'âcre odeur des temps, poudreuse et noire,

Parfois on trouve un vieux flacon qui se souvient,

D'où jaillit toute vive une âme qui revient.

Mille pensers dormaient, chrysalides funèbres,

Frémissant doucement dans les lourdes ténèbres,

Qui dégagent leur aile et prennent leur essor,

Teintés d'azur, glacés de rose, lamés d'or.

Voilà le souvenir enivrant qui voltige

Dans l'air troublé; les yeux se ferment; le Vertige

Saisit l'âme vaincue et la pausse à deux mains

Vers un gouffre obscurci de miasmes humains;

\footnotetext{
${ }^{24}$ Baudelaire 1984 (la traducción española ha sido modificada por mí donde lo consideré necesario).
} 
Il la terrasse au bord d'un gouffre séculaire, Où, Lazare odorant déchirant son suaire, Se meut dans son réveil le cadavre spectral D'un vieil amour ranci, charmant et sépulcral.

Ainsi, quand je serai perdu dans la mémoire Des hommes, dans le coin d'une sinistre armoire Quand on m'aura jeté, vieux flacon désolé, Décrépit, poudreux, sale, abject, visqueux, fêlé,

Je serai ton cercueil, aimable pestilence! Le témoin de ta force et de ta virulence, Cher poison préparé par les anges! liqueur Qui me ronge, ô la vie et la mort de mon coeur!

\section{EL FRASCO}

Hay perfumes fuertes para los que toda materia es porosa. Se diría que penetran el vidrio. $\mathrm{Al}$ abrir un cofrecito venido del Oriente en el que la cerradura rechina y gruñe chillonamente,

o en alguna casa desierta algún armario lleno del acre olor de los tiempos, polvoriento y negro, a veces se encuentra un viejo frasco que se recuerda, de donde surge toda viva un alma que retorna.

Mil pensares dormían, crisálidas fúnebres, estremeciéndose dulcemente en las pesadas tinieblas, que desprenden su ala y emprenden su vuelo, teñidas de azul, glaseadas de rosa, laminadas de oro.

He aquí el recuerdo embriagador que revolotea en el aire turbado; los ojos se cierran; el Vértigo toma el alma vencida y la arroja a dos manos a una sima oscurecida de miasmas humanas. 
La abate al borde de una sima secular, donde, Lázaro oloroso desgarrando su sudario, se mueve en su despertar el cadáver espectral, de un viejo amor rancio, encantador y sepulcral.

Así, cuando yo esté perdido en la memoria de los hombres, en el rincón de un siniestro armario cuando me hayan arrojado, viejo frasco desolado, decrépito, polvoriento, sucio, abyecto, viscoso, cascado,

¡yo seré tu ataúd, amable pestilencia!

El testigo de tu fuerza y de tu virulencia, ¡caro veneno preparado por los ángeles! ¡Licor que me roe! ¡Oh, la vida y la muerte de mi corazón!

\section{3. (Tercer "sentido") \\ El porvenir: dirección de la memoria}

\section{[...] un recuerdo necesita un porvenir. ${ }^{25}$}

El tiempo lleno es una maraña, pero en ella no estamos a oscuras. En la maraña del tiempo lleno, como en el caso de la luna, un recuerdo muestra iluminada la cara que da al porvenir. Estas constelaciones de presente, pasado y futuro que se dan cita en la memoria, son su respiración natural. La maraña del tiempo podría encontrarse en la figura de la memoria humana como palimpsesto, propuesta por Baudelaire: ${ }^{26}$

\footnotetext{
25 Véase Tadié 1999, 314: “[...] un souvenir a besoin d'avenir”.

${ }^{26}$ Baudelaire 1986, 256-257 (orig. Baudelaire 1975, 451-453): "Souvent des êtres, surpris par un accident subit, suffoqués brusquement par l'eau, et en danger de mort, ont vu s'allumer dans leur cerveau tout le théâtre de leur vie passée. Le temps a été annihilé, et quelques secondes ont suffi à contenir une quantité de sentiments et d'images équivalente à des années. Et ce qu'il y a de plus singulier dans cette expérience, que le hasard a amenée plus d'une fois, ce n'est pas la simultanéité de tant d'éléments qui furent successifs, c'est la réapparition de tout ce que l'être lui-même ne connaissait pas, mais qu'il est cependant forcé de reconnaître
} 
A menudo unos seres, sorprendidos por un accidente repentino, ahogados bruscamente por el agua, y en peligro de muerte, han visto encenderse en su cerebro todo el teatro de su vida pasada. El tiempo ha sido aniquilado, y han bastado algunos segundos para contener una cantidad de sentimientos y de imágenes equivalentes a años enteros. Y lo más singular de esta experiencia, que el azar ha originado en más de una ocasión, no es la simultaneidad de tantos elementos que fueron sucesivos, sino la reaparición de todo cuanto el propio ser no conocía ya, pero que, sin embargo, está obligado a reconocer como propio. Así pues, el olvido es sólo momentáneo; y en tales circunstancias solemnes, tal vez en la muerte y, generalmente, en las excitaciones intensas creadas por el opio, todo el inmenso y complicado palimpsesto de la memoria se desarrolla de un solo golpe, con todas sus capas superpuestas de sentimientos difuntos, misteriosamente embalsamados en lo que llamamos el olvido.

La cara iluminada de los recuerdos se muestra menos frecuentemente en el ocaso, cuando la luz del futuro se atenúa. O, dicho en términos de Koselleck: ${ }^{27}$ la vejez se ubica ahí donde la experiencia (es decir, el pasado) es cada vez mayor que la expectativa (futuro). Ahora bien, este camino ensombrecido de la memoria en la vejez responde a una concepción del sujeto que se gestó en el seno de la moral autónoma: ${ }^{28}$

comme lui étant propre. L'oubli n'est donc que momentané; et dans telles circonstances solennelles, dans la mort peut-être, et généralement dans les excitations intenses créées pas l'opium, tout l'immense et compliqué palimpseste de la mémoire se déroule d'un seul coup, avec toutes ses couches superposées de sentiments défunts, mystérieusement embaumés dans ce que nous appelons l'oubli".

${ }^{27}$ Koselleck 1993, 15-16. "La hipótesis es que en la determinación de la diferencia entre pasado y futuro o, dicho antropológicamente, entre experiencia y expectativa se puede concebir algo así como el 'tiempo histórico'. Ahora bien, ciertamente pertenece al hecho de que el hombre esté biológicamente condicionado, el que, con la edad, se modifique también la relación entre experiencia y expectativa, ya sea porque aquélla crezca y ésta disminuya, ya sea porque la una compense a la otra, ya sea porque los horizontes extrabiográficos se abran de forma intramundana o extramundana, ayudando a relativizar el tiempo final de una vida personal."

${ }^{28}$ El paradigma de la modernidad es el del yo autónomo, independiente y responsable de los propios actos. Este modelo heredero de la moral autónoma es el 
cuando uno se percibe solo y las propias fuerzas menguan, no hay coartada y es ignorado por el futuro. Sin embargo, desde la ética heterónoma, la perspectiva es diferente porque, en palabras de Tadié: "la memoria del muerto habita en el vivo, y resucita al muerto". ${ }^{29}$

Esta trasmigración de la memoria de los muertos a los vivos suena algo escandalosa, especialmente si le sumamos el componente de resurrección, y viene firmada por un neurocirujano, pero que escribe junto a un hombre de letras que es su hermano. Sin embargo, ése es el tono de la escritura del "des-astre": 30 cuando el futuro se descentra, se abre al porvenir -que siempre estuvo latente - y tiene la figura del otro. La condición es animarse a encarar el rostro de la fragilidad humana entendiendo que su efecto es contrario al de la Gorgona: en lugar de petrificar, la mirada de la vejez desmigaja toda certeza y pone al descubierto cierta miopía, una especie de sordera, en fin, una suave anestesia total, propia de nuestra cultura. Volviendo a la clasificación que hace Felisberto Hernández de los pensamientos: los ancianos atesoran los "pensamientos descalzos" que son los poros por los que nuestra civilización adultocéntrica respira; mientras ésta —atenta a la moda política y económica del momento — sólo ve su propia vestimenta, la vejez encarna la vulnerabilidad de la piel y lo no redituable para nuestro sistema. Lo provocativo en "la guerra del cerdo" es la imagen caricaturesca que devuelve el viejo

de la ética kantiana, que desconfía de cualquier acto no dictado por la propia razón. Emmanuel Levinas, filósofo contemporáneo, al definir al sujeto en tanto sujetado al prójimo, ubica a la ética heterónoma fuera de la oposición a la autonomía. La razón ética preoriginaria, que sostiene la responsabilidad para con el otro, tiene para este filósofo el estatuto de filosofía primera.

${ }^{29}$ Véase Tadié 1999, 324: "La mémoire du mort habite le vivant, et ressucite le mort".

${ }^{30}$ En alusión al sentido que le da Maurice Blanchot en La escritura del desastre (1990). Ese libro está inspirado en la ética heterónoma de Emmanuel Levinas. Blanchot sostiene que la escritura de Levinas descentra el pensamiento (quita el astro solar del centro del sistema: lo "des-astra"). 
a la sociedad joven: como en las buenas caricaturas, los viejos hacen resaltar los rasgos sobresalientes que una sociedad de jóvenes se niega a ver en sí misma. Como en toda guerra de exterminio, el inasimilable tiene algo demasiado familiar que incita a ser suprimido.

Así, los ancianos aparecen como seres improductivos que exigen derroche a una sociedad que interpreta la productividad como la fabricación de "necesidades" de consumo. Con su presencia, los viejos ponen en ridículo nuestra concepción instrumental del tiempo, el "time is money" que parece regir nuestras vidas de manera teletecnológica. ${ }^{31}$ Frente al tiempo rentable y productivo, cabe preguntarse por las potencialidades terapéuticas del ocio. El ocio no se reduce a pereza o inacción; Levinas lo llamaba "ejercicios de paciencia". Se trataría, en tanto jóvenes y adultos, de volver a aprender y a significar la experiencia del tiempo ocioso que la infancia sabe cultivar y la ancianidad se esfuerza por recordar. Un acercamiento no prejuicioso del ocio y la paciencia puede abrir el horizonte a una vejez diferente, que no se reduzca a la antesala de la muerte.

Hay más resonancias recíprocas entre la literatura, la medicina, la ética heterónoma y la política, de lo que podemos imaginar nosotros, herederos - a pesar nuestro- de un obstinado dualismo cartesiano y de una cuadrícula disciplinaria aplanadora. Una mirada tridimensional sobre la maraña del tiempo — junto a una escucha paciente — puede contribuir a darle la palabra a la memoria como sentido. Esta temporalidad no lineal y abierta al otro nos puede ayudar a aguzar los sentidos para intuir ese porvenir que se hospeda en aquellos cuyos pensamientos — propios de una razón ya no instrumental ni lógica sino imaginativa- danzan descalzos. Baudelaire ${ }^{32}$ en

\footnotetext{
${ }^{31}$ El neologismo derridiano nos parece preciso ya que caracteriza el control remoto propio de nuestro tiempo político.

${ }^{32}$ La escena final de "Los siete viejos" en los Cuadros parisienses [Tableaux parisiens], en Baudelaire 1984, p. 247 (la versión española ha sido modificada
} 
la escena final de "Los siete viejos" evoca esa danza del alma, largamente encorsetada:

Vanamente mi razón quería tomar el timón; la tempestad jugando desviaba sus esfuerzos, y mi alma bailaba, bailaba, la vieja gabarra sin mástiles, en un mar monstruoso y sin orillas!

\section{REFERENCIAS}

Alba, Víctor, 1992. Historia social de la vejez, Barcelona, Laertes. AréCHIgA, Hugo y Marcelino CEREIJIDo (coords.), 1999. El envejecimiento: sus desafíos y esperanzas, México, Siglo XXI / UnAm.

Baudelaire, Charles, 1975. Oeuvres complètes, edición Claude Pichois, vol. 1, Paris, Gallimard, NRF.

—, 1984. Obra poética completa, edición bilingüe, trad. Enrique Parellada, Barcelona, Río Nuevo.

—, 1986. Pequeños poemas en prosa. Los paraísos artificiales, trad. José A. Millán Alba, Madrid, Cátedra.

Beauvorr, Simone de, 1970. La vieillesse (1 y 2), Gallimard, Paris.

Benjamin, Walter, 1971. "Tesis de la filosofía de la historia”, en Angelus Novus, Barcelona, Edhasa.

Benoit-Lapierre, Nicole, et al., 1980. Vieillesse des pauvres. Les chemins de l'hospice, Paris, Les éditions ouvrières.

Bioy Casares, Adolfo, 1997. "Diario de la guerra del cerdo" (1969), en Obras completas, Novelas II, Bogotá, Norma.

—, 1997. "Planes para una fuga al Carmelo" en Obras completas, Cuentos II, Bogotá, Norma.

Blanchot, Maurice, 1990. La escritura del desastre [1983], trad. P. de Place, Caracas, Monte Ávila.

Blanck-Cereijido, Fanny y Marcelino Cereijido, 1999. La vida, el tiempo y la muerte, $2^{\mathrm{a}}$ ed., México, FCE.

—, 2000. La muerte y sus ventajas, $2^{\mathrm{a}}$ ed., México, FCE.

por mí). Orig. Baudelaire 1975, 451-453: "Vainemant ma raison voulait prendre la barre; / La tempête en jouant déroutait ses efforts, / Et mon âme dansait, dansait, la vieille gabarre / Sans mâts, sur une mer monstrueuse et sans bords!" 
Boвbio, Norberto, 1997. De Senectute [1996], trad. Esther Benítez, Madrid, Taurus.

Borges, Jorge Luis, 1974. "Funes el memorioso", en Obras completas 1923-1972, Buenos Aires, Emecé, pp. 485-490.

Cícerón, Marco Tulio, 1997. Catón el Mayor: de la vejez, versión de Julio Pimentel Álvarez, México, unAM.

Elias, Norbert, 1998. La solitude des mourants [1982], trad. del alemán al francés S. Muller, Paris, Christian Bourgois.

HernáNDEZ, Felisberto, 1999. "Tierras de la memoria", en Obras completas, vol. III, México, Siglo XXI.

Hesse, Hermann, 2000. Éloge de la vieillesse [1952], trad. del alemán al francés A. Cade, Paris, Calmann-Lévy.

Koselleck, Reinhart, 1993. Pasado Futuro. Para una semántica de los tiempos históricos [1979], Barcelona, Paidós.

Minors, Georges, 1987. Histoire de la vieillesse en Occident. De l'Antiquité à la Renaissance, Paris, Fayard.

NiETZsChe, Friedrich, 2000. Sobre la utilidad y los perjuicios de la historia para la vida [1874], trad. D. Garzón, Madrid, Edaf.

ShakesPeare, William, 1999. "Como gustéis", en Comedias, México, Conaculta / Océano.

SalvarezZA, Leopoldo (comp.), 2000. La vejez. Una mirada gerontológica actual, Buenos Aires, Paidós.

Sánchez-Salgado, Carmen Delia, 2000. Gerontología social, Buenos Aires, Espacio Editorial.

SonTAG, Susan, 1996. La enfermedad y sus metáforas [1977] y El sida y sus metáforas [1988], Madrid, Taurus.

TAdié, Jean-Yves y Marc, 1999. Le sens de la mémoire, Paris, Gallimard.

Thomas, Louis-Vincent, 1992. "Actitudes colectivas hacia los ancianos: problemas de civilización", en AAVV, La cuestión del envejecimiento. Perspectivas psicoanalíticas, Madrid, Biblioteca Nueva, pp. 133-167.

WIESEL, Elie, 1994. El olvidado [1989], trad. Enrique Sordo, Barcelona, Edhasa. 
Apéndice: Los viejos: nuestro futuro

(o "La lucidez es una forma de resistencia")

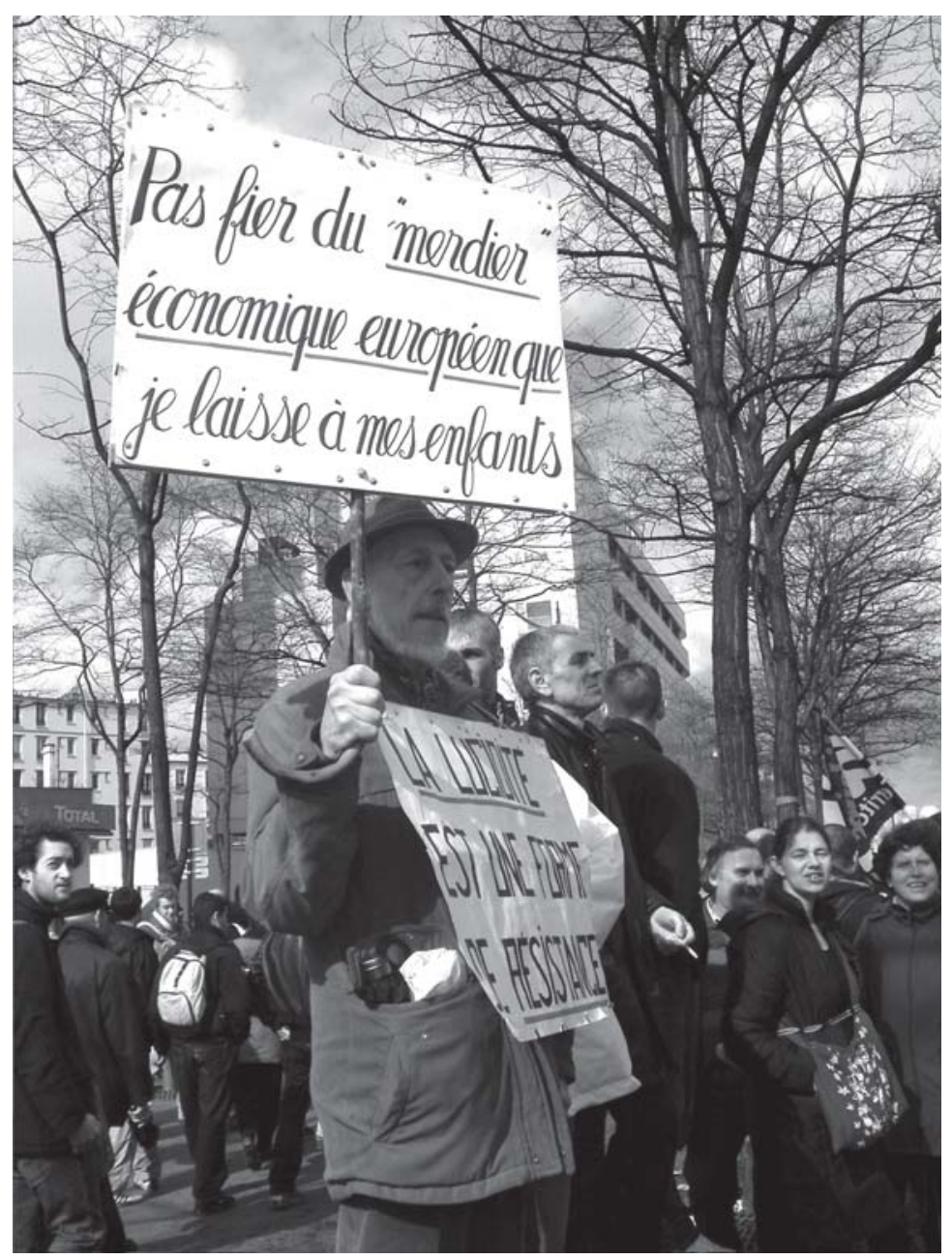

Fotografía tomada por Miriam Jerade en la primera manifestación de París contra el CPE (contrato de primer empleo), que pone de manifiesto la responsabilidad de un anciano ante el futuro de los jóvenes. 


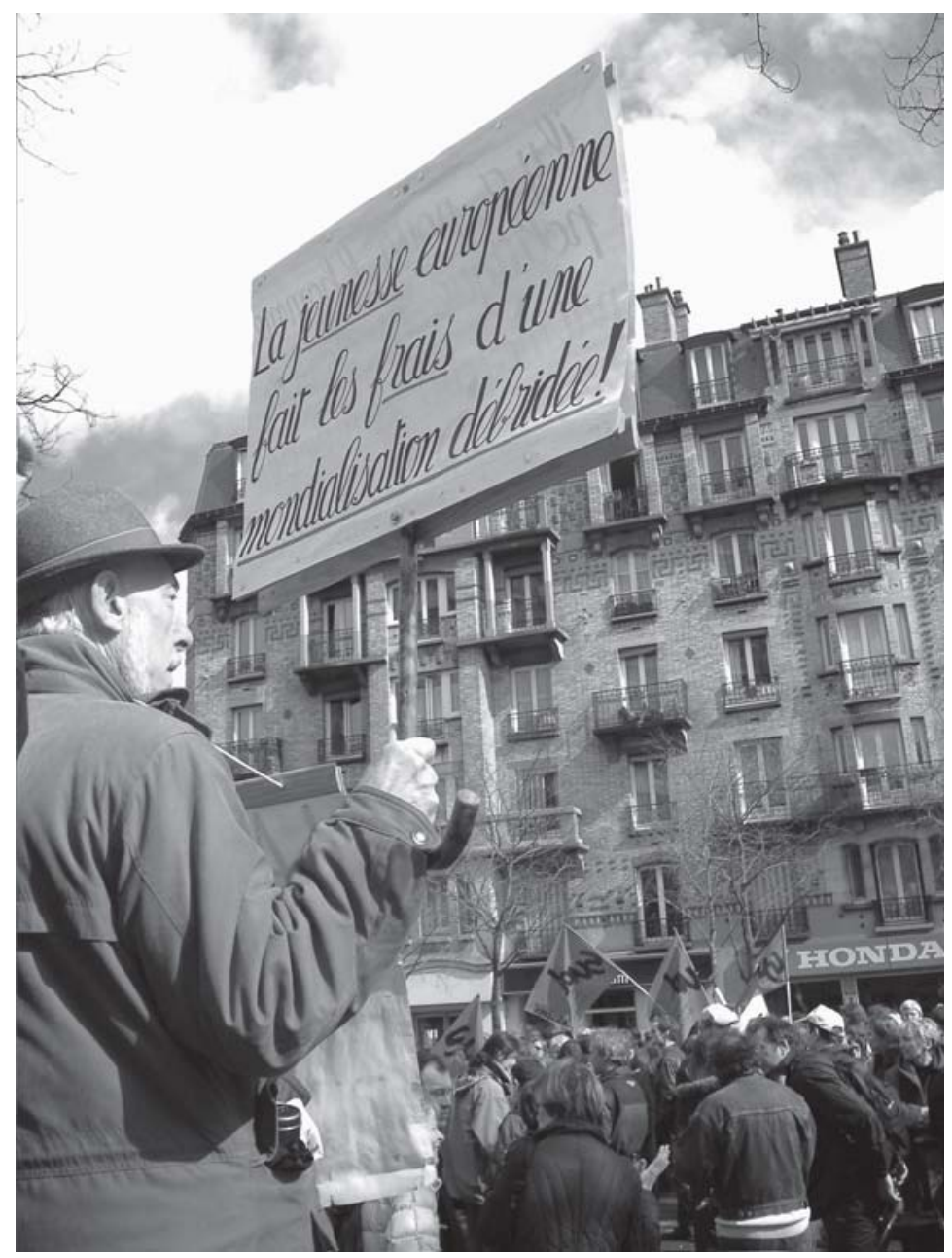

Fotografía tomada por Miriam Jerade 